\title{
Efficacy of coenzyme Q10 in mitigating spinal cord injury-induced osteoporosis
}

\author{
XUE-XUE ZHANG ${ }^{1}$, KE-JIAN QIAN ${ }^{2}$, YONG ZHANG ${ }^{1}$, ZHI-JIAN WANG ${ }^{1}$, YAN-BO YU ${ }^{1}$, \\ XIAO-JIAN LIU ${ }^{1}$, XIN-TIAN CAO ${ }^{1}$, YUN-HUA LIAO ${ }^{1}$ and DA-YING ZHANG ${ }^{1}$ \\ Departments of ${ }^{1}$ Pain and ${ }^{2}$ Intensive Care, The First Affiliated Hospital of Nanchang University, \\ Nanchang, Jiangxi 330006, P.R. China
}

Received July 17, 2014; Accepted March 26, 2015

DOI: $10.3892 / \mathrm{mmr} .2015 .3856$

\begin{abstract}
Spinal cord injury (SCI)-induced osteoporosis may cause mild trauma to bone and increase the risk of bone fracture. The present study aimed to investigate the efficacy of coenzyme Q (CoQ10) on SCI-induced osteoporosis in rats. SCI was induced by surgical transection of the cord at the T10-12 level. Animals were treated with CoQ10 (10 mg/kg; intragastrically) daily from $12 \mathrm{~h}$ after the surgery and over 10 subsequent days. At the end of the experimental period, blood was collected from the animals and femurs and tibiae were removed for evaluation using biochemical assays. Treatment with CoQ10 prevented SCI-induced bone loss by rescuing the decreased levels of bone mineral density and bone mineral content observed in the SCI rats. Furthermore, CoQ10 administration reduced bone malondialdehyde levels with a concomitant increase in superoxide dismutase levels, thus alleviating SCI-induced oxidative injury. In addition, serum inflammatory cytokine levels were markedly increased in rats post-SCI, which was attenuated by treatment with CoQ10. Finally, the osteoclast-specific genes receptor activator of nuclear factor kappa-B ligand and cathepsin $\mathrm{K}$ were significantly upregulated and the osteoblast-specific gene core-binding factor alpha 1 in the femur was downregulated following SCI, which was effectively restored following treatment with CoQ10. The results suggested that CoQ10 treatment may be effective in attenuating SCI-induced osteoporosis.
\end{abstract}

\section{Introduction}

Traumatic spinal cord injury (SCI) is a severe pathological event with consequences which are sustained throughout the life of the patient and eventually cause distress to the family

Correspondence to: Dr Da-Ying Zhang, Department of Pain, The First Affiliated Hospital of Nanchang University, 17 Yongwai Street, Nanchang, Jiangxi 330006, P.R. China

E-mail: zhangdaying921@gmail.com

Key words: spinal cord injury, osteoporosis, coenzyme Q10, oxidative stress, inflammation and society $(1,2)$. SCI activates an inflammatory cascade and during this, inflammatory cells from the circulation deteriorate vital organs, including the liver, kidney and lungs (3). Oxidative stress and inflammation may result in post-SCI pathogenesis, including cellular apoptosis, activation of free radicals and enhanced lipid peroxidation (LPO) with subsequent depletion of anti-oxidant agents, and have a pivotal role in SCI-induced secondary organ/tissue damage (4-7). One of the imminent consequences of SCI is a significant bone loss within a few months to a few years of injury (8), leading to fracture in $50 \%$ of patients with complete SCI. SCI-induced bone loss generally affects the lower limbs of rats due to longer bones as well as metaphysis, epiphysis and diaphysis of the femur and tibia of rats $(9,10)$. SCI-induced bone loss has significant morbidity and is likely to aggravate already profound disability. Treatment strategies to ameliorate bone loss after SCI by physical methods include passive standing, minimal electrical stimulation and body weight-supported treadmill training $(11,12)$. However, treatment using these strategies has no significant effects. Effective interventions may require targeting of multiple pathways to achieve significant clinical improvement after SCI, and complications including bone loss are warranted. Coenzyme Q10 (CoQ10) is a key mediator of the electron transfer reaction in the respiratory chain in mitochondria. A study suggested that CoQ10 has a free-radical-quenching effect and also displays insulin-like properties in diabetic patients (13). Previous studies provided evidence that CoQ10 has potent anti-oxidant activity $(14,15)$ and protective efficacy in experimental SCI (16). Previous pre-clinical studies demonstrated the anti-osteonecrotic effects (17) and the inhibitory effect on osteoclast differentiation in bone-marrow-derived monocytes and RAW 264.7 cells of CoQ10, which are mediated by its free-radical-scavenging mechanism (18). However, to the best of our knowledge, the effect of CoQ10 in SCI-induced bone loss has not been studied to date. Therefore, the present study was designed to evaluate the therapeutic efficacy of CoQ10 against bone loss induced by SCI in rats.

\section{Materials and methods}

Chemicals. Co-enzyme Q10, superoxide dismutase (SOD) and malondialdehyde (MDA) diagnostic kits were obtained from 
Sigma-Aldrich (St. Louis, MO, USA). All other chemicals were of the highest available commercial grade.

Animals. Forty male Sprague-Dawley rats (8 weeks-old, weighing 170-200 g) were obtained from the animal facility at Nanchang University (Nanchang, China). The animals were maintained under standard laboratory conditions of relative humidity $(55 \pm 5 \%)$, temperature $\left(25 \pm 2^{\circ} \mathrm{C}\right)$, and light $(12 \mathrm{~h}$ light/dark cycle). They were fed standard diet pellets and water was provided ad libitum. The study was approved by the ethics committee of The First Affiliated Hospital of Nanchang University, (Nanchang, China).

Animal model of SCI. The rats were anesthetized by administration of xylazine + ketamine [10 and $75 \mathrm{mg} / \mathrm{kg}$, respectively; intraperitoneally (i.p.)]. After the dorsum of the animals was shaved and sterilized, an incision was made from the posterior to the lower thoracic region. Laminectomy (thoracic T10-T12 vertebrae) was performed to expose the spinal cord alone (sham group). After the laminectomy, the lower thoracic cord was subsequently completely transected with fine sterilized micro scissors (SCI group) under a magnifier. Both stumps of the spinal cord were gently lifted away to create a 1-2-mm gap, which was filled with sponge gel. The muscle fascia and skin were sutured, and the rats were returned to their cages. After completion of surgery, the animals received a bolus of Lactate Ringers solution ( $5 \mathrm{ml}$; i.p.) to compensate for blood loss, and antibiotic cover (systemic gentamycin, $50 \mathrm{mg} / \mathrm{kg}$ intramuscularly; local treatment with neosporin ointment) was provided. Furthermore, the SCI rats received daily assistance in bladder emptying until spontaneous miction recovered.

Evaluation of locomotor functions. The quality of locomotion was assessed using the Basso, Beattie, and Bresnahan (BBB) locomotor rating score (19).

Study design. Sprague-Dawley rats were divided into four groups ( $\mathrm{n}=10$ each) and treated for 10 days as follows: i) Group I - sham-operated rats (Sham); ii) Group II - SCI rats (SCI); iii) Group III - sham-operated rats receiving CoQ10 $(10 \mathrm{mg} / \mathrm{kg}$ ) intragastrically for 10 days (sham + CoQ10); iv) Group IV - SCI rats receiving CoQ10 $(10 \mathrm{mg} / \mathrm{kg})$ for 10 days $(\mathrm{SCI}+\mathrm{CoQ} 10)$.

At the end of the experimental period, rats were fasted overnight and sacrificed by decapitation. Blood was collected in heparinized BD vacutainer (BD Biosciences, San Jose, CA, USA) and serum samples were collected by centrifugation at $450 \mathrm{x} \mathrm{g}$ for $20 \mathrm{~min}$. Femur and tibiae were immediately excised, rinsed in ice-cold saline to remove the blood and stored at $-80^{\circ} \mathrm{C}$ until required.

Preparation of bone homogenate. Frozen bone samples $(150 \mathrm{mg})$ were minced in a phosphate buffer and homogenized in a MagNA Lyser instrument (Roche Applied Science, Penzberg, Germany). Samples were centrifuged three times at $530 \mathrm{x} \mathrm{g}$ for $20 \mathrm{sec}$ with intermediate cooling $5 \mathrm{~min}$ in the MagNA Lyser Cooling Block. The tissue homogenate was then centrifuged at $10,000 \mathrm{x}$ g at $4^{\circ} \mathrm{C}$ for $10 \mathrm{~min}$. The supernatant was separated, stored at $-80^{\circ} \mathrm{C}$ and used for further biochemical analysis.
Measurements of bone mineral content (BMC) and bone mineral density $(B M D)$. At the end of experiment, one half of the experimental rats $(n=5)$ were anesthetized using xylazine and ketamine (10 and $75 \mathrm{mg} / \mathrm{kg}$, respectively i.p.; Sigma-Aldrich) and the BMD and BMC of the left femur and tibia were estimated using dual energy X-ray absorptiometry instrument (DEXA, Norland X46; Norland, Fort Atkinson, WI, USA) equipped with dedicated software (version 3.9.6) for small animal measurements. The BMC (expressed in grams) was divided by the area of the site that was scanned to obtain the BMD (expressed in $\mathrm{g} / \mathrm{cm}^{2}$ ) (20).

Assessment of systemic oxidative stress. SOD levels of femur and tibiae bone homogenate were estimated by the method of Kakkar et al (21). The inhibition of reduction of nitro blue tetrazolium to blue formazan in the presence of phenazine methosulphate and nicotinamide adenine dinucleotide was measured at $560 \mathrm{~nm}$ using n-butanol as blank with a Shimadzu-1601 PC UV-Visible scanning spectrophotometer (Shimadzu Corp., Kyoto, Japan). One unit (U) of enzyme activity was defined as the amount of enzyme that inhibits the reaction rate by $50 \%$ in $1 \mathrm{~min}$ under the defined assay conditions and the results are expressed as U/mg protein.

MDA levels were determined by the method of Ohkawa et al (22). Briefly, $0.5 \mathrm{ml}$ femur and tibiae bone homogenate tissue was mixed with $2.5 \mathrm{ml} 20 \%$ trichloroacetic acid in a $10-\mathrm{ml}$ centrifuge tube. To the mixture, $1 \mathrm{ml} 0.67 \%$ thiobarbituric acid was added, followed by mixing and heating for $30 \mathrm{~min}$ in a boiling water bath followed by rapid cooling. Subsequently, $4 \mathrm{ml}$ n-butyl-alcohol was added followed by mixing. The mixture was centrifuged at $154 \mathrm{x} \mathrm{g}$ for $10 \mathrm{~min}$. The resultant n-butyl-alcohol layer was separated and its MDA content was determined from the absorbance at $535 \mathrm{~nm}$. The results are expressed as $\mathrm{nM} / \mathrm{mg}$ protein.

Assay for inflammatory cytokine levels. Concentrations of interleukin (IL)- 6 and tumor necrosis factor (TNF)- $\alpha$ were determined in serum using commercially available TNF- $\alpha$ and IL-6 ELISA kits (USCN LIFE; Wuhan EIAab Science Co., Ltd, Wuhan, China).

Bone gene expression analysis. The mRNA expression of genes relevant to osteoclastogenesis [receptor activator of nuclear factor kappa-B ligand (RANKL) and cathepsin K] and osteoblastogenesis [core-binding factor alpha 1 (Cbfa1)] in the femur, was investigated using reverse transcription quantitative polymerase chain reaction (RT-qPCR) analysis. Briefly, the frozen samples of distal femurs were finely ground into powder while immersed in liquid nitrogen using a mortar and pestle free from RNase. The frozen powder was transferred into a vial containing TRIzol (Invitrogen Life Technologies Carlsbad, CA, USA) and extraction of total RNA was performed using the QuantiTect ${ }^{\mathrm{TM}}$ nSYBR $^{\circledR}$ Green PCR kit (Shanghai Tiangen Chemical Co., Ltd., Shanghai, China) in accordance with the manufacturer's instructions. $1 \mu \mathrm{g}$ total RNA was digested with $10 \mu \mathrm{l}$ DNase I (Invitrogen Life Technologies) and from this $5 \mu \mathrm{l}$ (500 ng) was reverse transcribed with $200 \mathrm{U}$ SuperScript II (Invitrogen Life Technologies) using $500 \mathrm{ng}$ oligo-dT and $250 \mathrm{ng}$ random hexamers. RT-PCR analysis was performed 
Table I. Sequences of oligonucleotides used as primers.

\begin{tabular}{|c|c|c|c|c|c|}
\hline Gene (abbreviation) & Gene (full name) & ID & Sequence $\left(5^{\prime} \rightarrow 3^{\prime}\right)$ & $\operatorname{Tm}\left({ }^{\circ} \mathrm{C}\right)$ & Size (bp) \\
\hline RANKL & $\begin{array}{l}\text { Receptor activator of } \\
\text { nuclear factor- } \kappa \mathrm{B} \text { ligand }\end{array}$ & 117516 & $\begin{array}{l}\text { Forward: TCAGGAGTTCCA } \\
\text { GCTATGAT } \\
\text { Reverse: CCATCAGCTGAA } \\
\text { GATAGTCC }\end{array}$ & 55 & 298 \\
\hline Cathepsin K & Cathepsin $\mathrm{K}$ & 29175 & $\begin{array}{l}\text { Forward: GAGACATGACCAGC } \\
\text { GAAGAA } \\
\text { Reverse: CACATATTGGAAGGC } \\
\text { AGTGG }\end{array}$ & 56 & 332 \\
\hline Cbfa1 & Core binding factor alpha 1 & 367218 & $\begin{array}{l}\text { Forward: CGAAATGCCTCTGC } \\
\text { TGTTAT } \\
\text { Reverse: TTCTGTCTGTGCCTT } \\
\text { CTTGG }\end{array}$ & 53 & 194 \\
\hline GAPDH & $\begin{array}{l}\text { Glyceraldehyde 3-phosphate } \\
\text { dehydrogenase }\end{array}$ & 2597 & $\begin{array}{l}\text { Forward: ACCACAGTCCATGC } \\
\text { CATCAC } \\
\text { Reverse: TCCACCACCCTGTTG } \\
\text { CTGTA }\end{array}$ & 60 & 452 \\
\hline
\end{tabular}
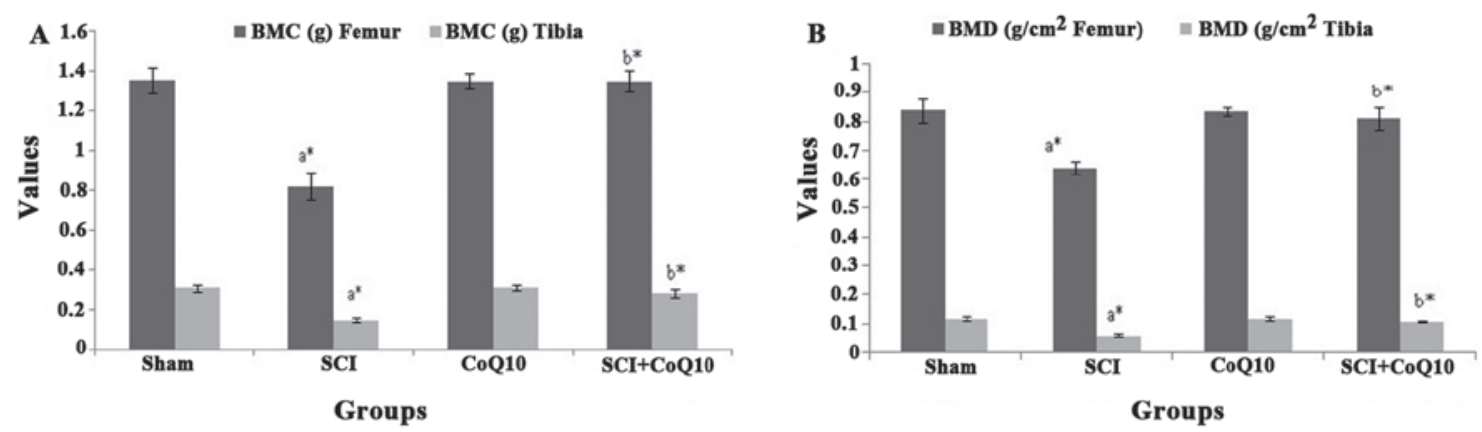

Figure 1. Efficacy of CoQ10 on bone strength markers in SCI-induced osteoporotic rats. (A) BMC $\left(\mathrm{g} / \mathrm{cm}^{2}\right)$ and (B) BMDs (in grams). Values are expressed as the mean \pm standard deviation for five rats in each group. " $\mathrm{P}<0.05$ for comparisons between a Sham and SCI or ${ }^{\mathrm{b}} \mathrm{SCI}$ and $\mathrm{SCI}+\mathrm{CoQ} 10$. SCI, spinal cord injury; BMD, bone mineral density; BMC, bone mineral content; Co, coenzyme.

using QuantiTect ${ }^{\mathrm{TM}}$ nSYBR ${ }^{\circledR}$ Green PCR (Tiangen, Shanghai, China) according to the manufacturer's instructions. The RT-PCR data were based on SYBR green amplification. The sequences of primers are listed in Table I. The highly specific measurement of mRNA was performed using the Light Cycler system (Bio-Rad Laboratories, Hercules, CA, USA). PCR amplification was performed in 96-well optical reaction plates for 40 cycles, with cycles of $94^{\circ} \mathrm{C}$ for $30 \mathrm{sec}$, $58-63^{\circ} \mathrm{C}$ for $30 \mathrm{sec}$ and $72^{\circ} \mathrm{C}$ for $60 \mathrm{sec}$. Each sample was run and analyzed in duplicate. GAPDH mRNA as an internal control was used to normalize the data to determine the relative expression of the target genes. The fold changes relative to values of the sham-operated group were obtained and used to express the changes in gene expression.

Statistical analysis. Values are expressed as the mean \pm standard deviation. The results were statistically analyzed by one-way analysis of variance followed by Dunnet's $t$-test using SPSS software version 13.0 (SPSS, Inc., Chicago, IL, USA).
$\mathrm{P}<0.05$ was considered to indicate a statistically significant difference between values.

\section{Results}

CoQ10 alleviates decreased BMD and BMC in rats following $S C I$. The BMD and BMC of femur and tibia were significantly decreased in the SCI group as compared with that in the sham group $(\mathrm{P}<0.05)$. Treatment with CoQ10 $(10 \mathrm{mg} / \mathrm{kg})$ significantly alleviated the decreasing effect of SCI on BMC (Fig. 1A) and BMD (Fig. 1B) $(\mathrm{P}<0.05)$. Treatment of sham-operated rats with CoQ10 had no significant effect on these parameters.

CoQ10 alleviates oxidative stress in bones following SCI. Compared with the sham group, SOD levels in femur and tibia were significantly depleted in SCI rats $(\mathrm{P}<0.05)$. However, treatment with CoQ10 effectively restored the SOD status to normal levels (Fig. 2A). Furthermore, MDA, a toxic adduct formed during lipid peroxidation, was significantly elevated 

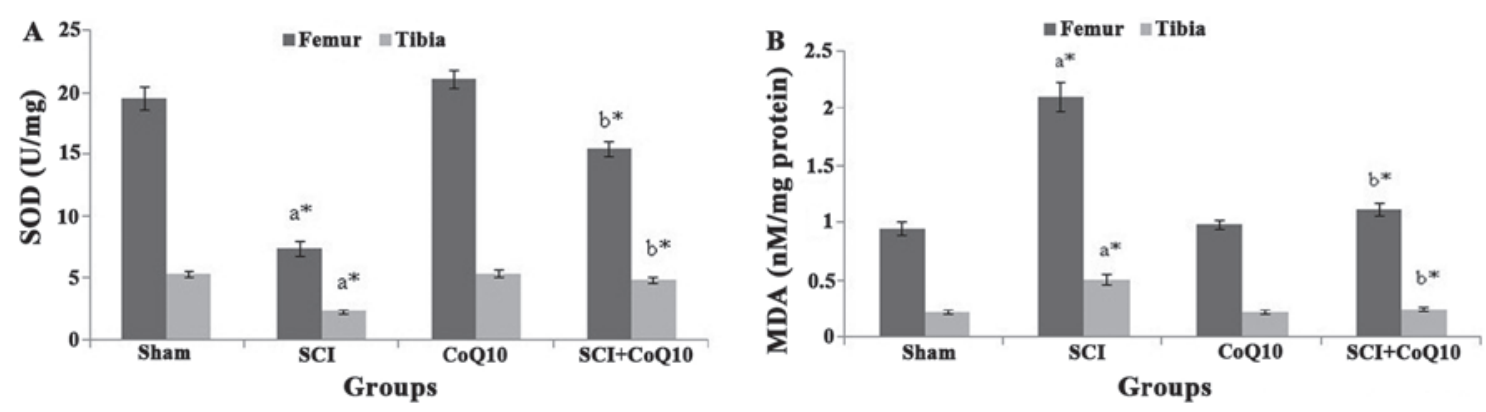

Figure 2. Effect of CoQ10 on levels of oxidative stress markers in rats with SCI. (A) SOD levels and (B) MDA levels. Values are expressed as the mean \pm standard deviation for seven rats in each group. "P<0.05 for comparisons between aSham and SCI or ${ }^{\mathrm{b}} \mathrm{SCI}$ and SCI + CoQ10. SCI, spinal cord injury; SOD, superoxide dismutase; Co, coenzyme; MDA, malondialdehyde.

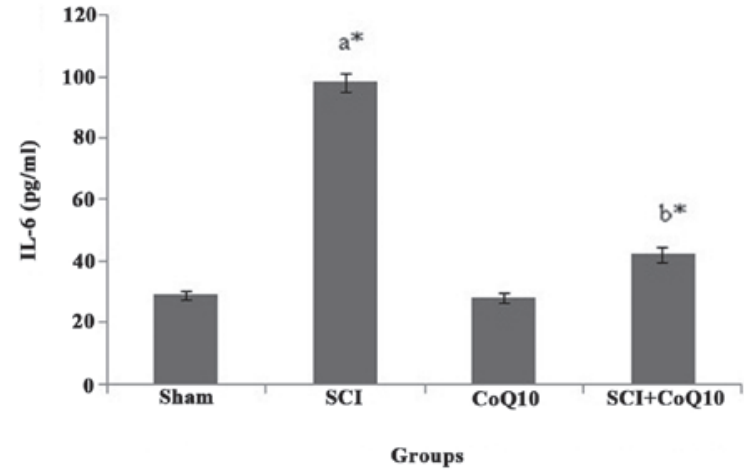

Figure 3. IL-6 levels are increased in rats with SCI, which is attenuated by treatment with CoQ10. Values are expressed as the mean \pm standard deviation for seven rats in each group. ${ }^{\mathrm{P}}<0.05$ for comparisons between ${ }^{\mathrm{a}} \mathrm{Sham}$ and SCI or ${ }^{b} \mathrm{SCI}$ and $\mathrm{SCI}+\mathrm{CoQ} 10$. SCI, spinal cord injury; IL, interleukin; Co, coenzyme.

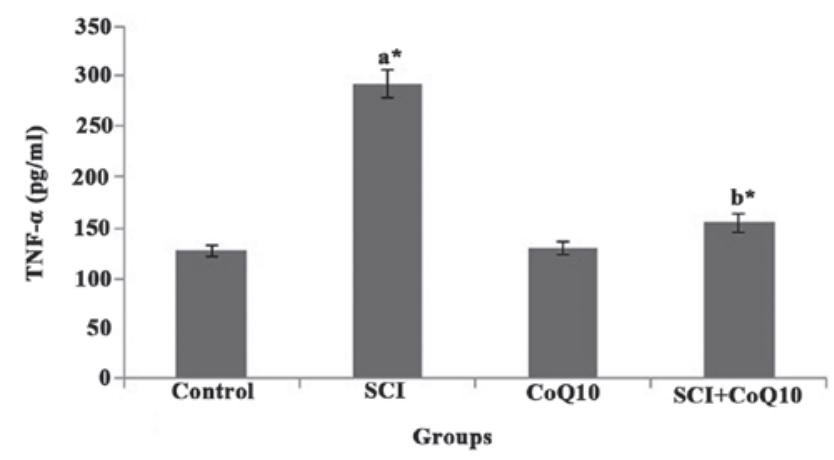

Figure 4. TNF- $\alpha$ levels are increased in rats with SCI, which is attenuated by treatment with $\mathrm{CoQ} 10$. Values are mean $\pm \mathrm{SD}$ for seven rats in each group. ${ }^{*} \mathrm{P}<0.05$ for comparisons between a Sham and SCI or ${ }^{\mathrm{b}} \mathrm{SCI}$ and $\mathrm{SCI}+\mathrm{CoQ} 10$ $\mathrm{SCI}$, spinal cord injury; Co, coenzyme; TNF, tumor necrosis factor.

in the femur and tibia of SCI rats compared with that in the sham operated rats $(\mathrm{P}<0.05)$. However, treatment with $\mathrm{CoQ} 10$ significantly attenuated the elevated MDA in femur and tibia to normal levels $(\mathrm{P}<0.05)$ (Fig. 2B).

CoQ10 reduces serum inflammatory markers in SCI rats. In the present study, SCI rats displayed a significant elevation of serum inflammatory cytokines IL-6 (Fig. 3) and TNF- $\alpha$ (Fig. 4) $(\mathrm{P}<0.05)$. Oral administration of CoQ10 effectively reduced the IL- 6 and TNF- $\alpha$ levels in serum to normal levels and thus minimized inflammation.

CoQ10 attenuates SCI-induced increases in osteoclastogenesis gene expression in femurs of rats. The mRNA levels of osteoclast-specific genes RANKL (Fig. 5A) and cathepsin K (Fig. 5B) were increased in femurs of SCI rats. Of note, treatment with CoQ10 significantly decreased the RANKL and cathepsin $\mathrm{K}$ mRNA levels in femurs $(\mathrm{P}<0.05)$.

CoQ10 attenuates SCI-induced decreases in osteoblastogenesis gene expression in femurs of rats. The mRNA levels of the osteoblast-specific gene Cbfal (Fig. 6) were decreased in femurs of SCI rats. However, administration of CoQ10 rescued the mRNA levels of Cbfa1 in the femurs of rats following SCI $(\mathrm{P}<0.05)$.

\section{Discussion}

Therapeutic agents including bisphosphonates, estrogen and raloxifene have been implicated in the treatment of bone diseases. However, despite their beneficial effects, they exert certain adverse effects, including thromboembolism and oesophageal irritation (23-25). Therefore, the discovery of novel drugs to treat bone-associated disorders is required. CoQ10 may be a candidate for the prevention of osteoporosis, as it displays cytoprotective properties and acts as an effective free radical scavenger.

The present study explored the efficacy of CoQ10 on bone loss induced by SCI in a murine model. Complete SCI at the lower segment of the thoracic cord of rats is routinely used in pre-clinical studies on the pathogenesis of SCI-induced osteoporosis $(8,26,27)$. It induces severe forms of osteoporosis and an array of factors increasing the susceptibility to osteoporosis, including carrying heavy objects, neural lesions and hormonal imbalance (28). Further direct denervation of bone and indirect alteration of vasoregulation are attributed to SCI-mediated osteoporosis (29). Furthermore, negative imbalance of $\mathrm{Ca}^{2+}$ mediated by altered hormone levels is involved in the post-SCI osteoporosis (30). Previous studies on rodents and humans suggested that following SCI, bone resorption is increased due to osteoclast activation $(31,32)$. Morse et al (33) showed that ten days post-SCI, the bone formation rate in rats at the distal femur was significantly lower than that in sham-operated rats. Furthermore, a significant reduction in 

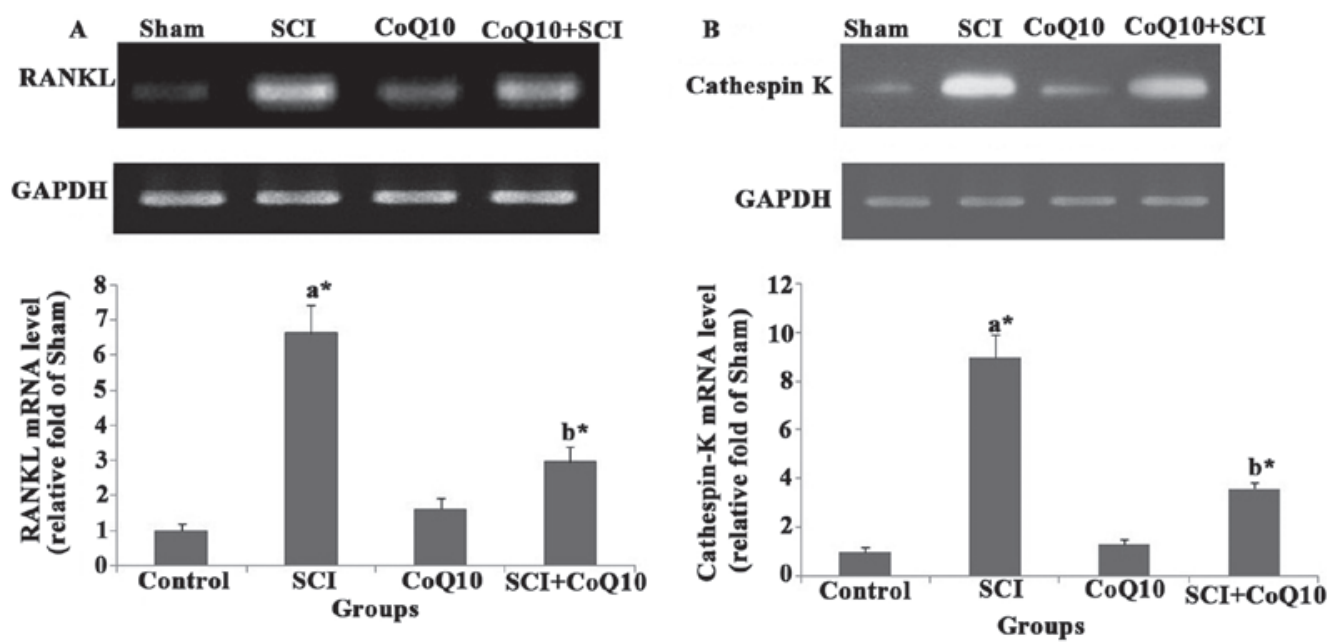

Figure 5. Effect of CoQ10 on osteoclast gene expression in femurs of SCI rats. (A) RANKL mRNA expression and its relative fold change. (B) Cathepsin K mRNA expression and its relative fold change. Values are expressed as the mean \pm standard deviation for three rats in each group. "P $<0.05$ for comparisons between ${ }^{\mathrm{a} S h a m}$ and SCI or ${ }^{\mathrm{b}} \mathrm{SCI}$ and SCI + CoQ10. SCI, spinal cord injury; Co, coenzyme; RANKL, receptor ligand of nuclear factor- $\mathrm{kB}$ ligand.
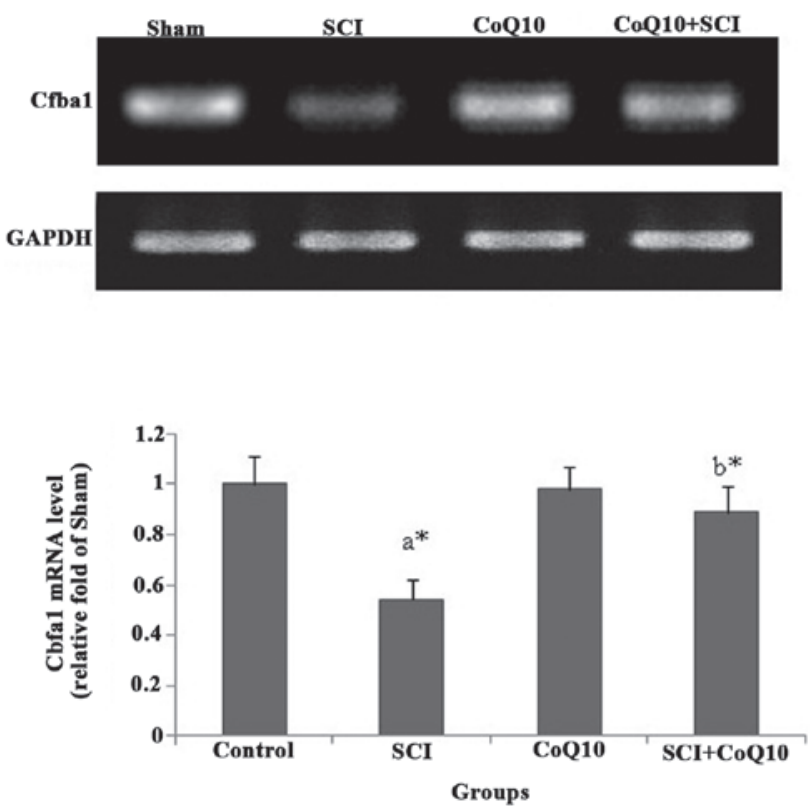

Figure 6. Cbfa 1 mRNA expression and its relative fold change. Values are expressed as the mean \pm standard deviation for three rats in each group. ${ }^{*} \mathrm{P}<0.05$ for comparisons between ${ }^{\mathrm{S}} \mathrm{Sham}$ and $\mathrm{SCI}$ or ${ }^{\mathrm{b}} \mathrm{SCI}$ and $\mathrm{SCI}+\mathrm{CoQ} 10$ SCI, spinal cord injury; Co, coenzyme; Cbfa, core binding factor alpha.

the number of osteoclasts was observed in the distal femur five days post-SCI.

It is essential to asses and monitor post-SCI osteoporosis to minimize the prevalence of fracture. BMD and BMC are reliable markers in the assessment of osteoporosis and clearly show the fracture risk in the majority of patients (34). In the present study, rats displayed a significant decrease in BMD and $\mathrm{BMC}$ of femur and tibia following SCI as compared with those in the sham group, indicating that tibial and bone loss had occurred. Treatment with CoQ10 restored the BMC and BMD to normal, which may be due to the re-establishment of bone balance through preventing an increase in the number of osteoclasts by inhibiting osteoclast maturation (18).
Reactive oxygen species have a pivotal role in the development of secondary complications following SCI (35). In the present study, SCI rats displayed elevated levels of femoral and tibial MDA with a concomitant decrease in the levels of the antioxidant enzyme SOD. These depleted levels of SOD may have been due to the involvement of SOD in scavenging the free radicals generated by SCI. Thus, these results demonstrated the role of oxidative stress in the progression of osteoporosis following SCI, which is in corroboration with the results of a previous study (36). Treatment with CoQ10 mitigated the oxidative stress and restored the levels of MDA and SOD to normal levels. Thus, the preventive effect of CoQ10 against bone loss may be due to its free radical scavenging properties (37).

Elevated cytokine levels within the bone have been involved in SCI-induced osteoporosis. Demulder et al (38) reported that levels of IL-6 were increased in serum and bone samples of the sternum and iliac crest from patients with SCI. Thus, the elevated cytokines may lead to the recruitment of osteoclasts from marrow precursors and enhance osteoclast activity in bones. In the present study, elevated serum levels of IL-6 were significantly diminished by CoQ10 treatment, which is in corroboration with previous study (39). Furthermore, osteoclasts ware highly activated and osteoblasts are suppressed by the inflammatory cytokine TNF- $\alpha$ via the RANKL and osteoprotegerin (OPG) system. In the present study, the elevated serum levels of TNF- $\alpha$ in rats following SCIs were significantly reduced by CoQ10 treatment. Previous studies reported the potential of CoQ10 to decrease TNF- $\alpha(40,41)$. Thus, the anti-osteoporotic effect rendered by CoQ10 may be mediated through an anti-cytokine mechanism.

Previous studies reported increased bone resorption activity post-SCI. RANKL, which is expressed on the surface of bone marrow stromal/osteoblast precursor cells, $\mathrm{T}$ cells and B cells, is the prime molecule involved in osteoclast synthesis. RANKLs bind to their cognate receptors, RANK, on osteoclast lineage cells, and are neutralized by the soluble, decoy receptor, OPG, which is also produced by osteoblastic 
lineage cells (42-44). A previous study showed that RANKL mRNA and protein expression in cultured osteoblast-like cells from SCI rats was significantly increased and resulted in increased osteoclastogenesis, thus leading to osteoporosis after SCI (10).In the present study, rats displayed increased mRNA expression of RANKL in the femur following SCI and CoQ10 treatment significantly reversed the altered mRNA expression to normal levels (45).

Cathepsin $\mathrm{K}$ is primarily expressed in osteoclasts (46) and has a pivotal role in the degradation of the collagen matrix components of bone (predominantly type-I collagen) at acidic $\mathrm{pH}$. Based on human genetics $(47,48)$, experimental genetics in mice (49), substrate preference and cellular distribution (50), the pivotal role of cathepsin $\mathrm{K}$ in osteoclastic bone resorption has been demonstrated. In the present study, rats displayed increased mRNA expression of Cathepsin K in the femur post-SCI. Of note, CoQ10 treatment downregulated cathepsin $\mathrm{K}$ in the femurs of rats following SCI and thus prevented the degradation of the bone matrix.

The bone-specific Cbfa1 gene is a runt-domain-containing transcription factor essential for osteoblastic differentiation and bone formation during embryogenesis and post-natal life (51). Cbfa1 has two vital functions - promotion of the initial phase of differentiation from mesenchymal stem cells to pre-osteoblasts and inhibition of pre-osteoblast differentiation to mature osteoblasts (52). As expected, in the present study, rats displayed decreased mRNA expression of Cbfa1 in the femur post-SCI. However, CoQ10 rescued Cbfa1 mRNA expression and promoted bone matrix production.

In conclusion, treatment with CoQ10 mitigated the bone loss in rats following SCI by increasing BMD and BMC levels, attenuating oxidative stress, debilitating the cytokine levels, depressing RANKL and cathepsin K expression, as well as restoring Cbfa1 mRNA levels. Thus, CoQ10 may be an effective nutraceutical to ameliorate osteoporosis after SCI. However, further molecular studies are warranted to explore the feasibility of using CoQ10 as an anti-osteoporotic agent.

\section{References}

1. Carlson GD and Gorden C: Current developments in spinal cord injury research. Spine J 2: 116-128, 2002.

2. Becker D, Sadowsky CL and McDonald JW: Restoring function after spinal cord injury. Neurologist 9: 1-15, 2003.

3. Bao F, Brown A, Dekaban GA, Omana V and Weaver LC: CD11d integrin blockade reduces the systemic inflammatory response syndrome after spinal cord injury. Exp Neurol 231: 272-283, 2011.

4. Balentine JD: Pathology of experimental spinal cord trauma I. The necrotic lesion as a function of vascular injury. Lab Invest 39: 236-253, 1978.

5. Wrathall JR, Teng YD and Choiniere D: Amelioration of functional deficits from spinal cord trauma with systemically administered NBQX, an antagonist of non-N-methyl-D-aspartate receptors. Exp Neurol 137: 119-126, 1996.

6. Bao F, John SM, Chen Y, Mathison RD and Weaver LC: The tripeptide phenylalanine-(d) glutamate-(d) glycine modulates leukocyte infiltration and oxidative damage in rat injured spinal cord. Neuroscience 140: 1011-1022, 2006.

7. Liu NK, Zhang YP, Titsworth et al: A novel role of phospholipase A2 in mediating spinal cord secondary injury. Ann Neurol 59: 606-619, 2006.

8. Jiang SD, Jiang LS and Dai LY: Mechanisms of osteoporosis in spinal cord injury. Clin Endocrinol (Oxf) 65: 555-565, 2006
9. Morse L, Teng YD, Pham L, et al: Spinal cord injury causes rapid osteoclastic resorption and growth plate abnormalities in growing rats (SCI-induced bone loss in growing rats). Osteoporos Int 19: 645-652, 2008.

10. Jiang SD, Jiang LS and Dai LY: Spinal cord injury causes more damage to bone mass, bone structure, biomechanical properties and bone metabolism than sciatic neurectomy in young rats. Osteoporos Int 17: 1552-1561, 2006.

11. Needham-Shropshire BM, Broton JG, Klose KJ, Lebwohl N, Guest RS and Jacobs PL: Evaluation of a training program for persons with SCI paraplegia using the Parastep 1 ambulation system, part 3: lack of effect on bone mineral density. Arch Phys Med Rehabil 78: 799-803, 1997.

12. Giangregorio LM, Hicks AL, Webber CE, et al: Body weight supported treadmill training in acute spinal cord injury: impact on muscle and bone. Spinal Cord 43: 649-657, 2005.

13. Matsumura T, Saji S, Nakamura R and Folkers K: Evidence for enhanced treatment of periodontal disease by therapy with coenzyme Q. Intl J Vitamin Nutr Res 43: 537-548, 1973.

14. Deichmann R, Lavie C and Andrews S: Coenzyme q10 and statin-induced mitochondrial dysfunction. Ochsner J 10: 16-21, 2010.

15. Kalayci M, Unal MM, Gul S, et al: Effect of coenzyme Q10 on ischemia and neuronal damage in an experimental traumatic brain-injury model in rats. BMC Neurosci 12: 75, 2011.

16. Kerimoğlu A, Paşaoğlu O, Kanbak G, Hanci V, Ozdemir F and Atasoy MA: Efficiency of coenzyme Q (10) at experimental spinal cord injury. Ulus Travma Acil Cerrahi Derg 13: 85-93, 2007 (In Turkish).

17. Kömürcü E, Oktay M, Kaymaz B, Hatay Gölge U, Göksel F and Nusran G: Preventive effects of coenzyme Q10 (CoQ10) on steroid-induced osteonecrosis in rats. Acta Orthop Traumatol Turc 48: 217-222, 2014.

18. Moon HJ, Ko WK, Han SW, Kim DS, Hwang YS, Park HK and Kwon IK: Antioxidants, like coenzyme Q10, selenite and curcumin, inhibited osteoclast differentiation by suppressing reactive oxygen species generation. Biochem Biophys Res Commun 418: 247-253, 2012.

19. Basso DM, Beattie MS and Bresnahan JC: Graded histological and locomotor outcomes after spinal cord contusion using the NYU weight-drop device versus transection. Exp Neurol 139: 244-256, 1996.

20. Jo HJ and Choi M: Effects of isoflavone supplementation on the bone mineral density of growing female rats. Nutr Res Pract 2: 68-73, 2008.

21. Kakkar P, Das B and Viswanathan PN: A modified spectrophotometric assay of superoxide dismutase. Indian J Biochem Biophys 21: 130-132, 1984.

22. Ohkawa H, Ohishi $\mathrm{N}$ and Yagi K: Assay for lipid peroxidation in animal tissues by thiobarbituric acid reaction. Anal Biochem 95: 351-358, 1979.

23. Lloyd M: Treatment of postmenopausal osteoporosis. N Engl J Med 338: 739-746, 1998.

24. Rodan GA and Martin TJ: Therapeutic approaches to bone diseases. Science 289: 1508-1514, 2000.

25. Rachner TD, Khosla S and Hofbauer LC: Osteoporosis: now and the future. Lancet 377: 1276-1287, 2011.

26. Jiang SD, Jiang LS and Dai LY: Changes in bone mass, bone structure, bone biomechanical properties and bone metabolism after spinal cord injury: a 6-month longitudinal study in growing rats. Calcif Tissue Int 80: 167-175, 2007.

27. Liu D, Zhao CQ, Li H, Jiang SD, Jiang LS and Dai LY: Effects of spinal cord injury and hindlimb immobilization on sublesional and supralesional bones in young growing rats. Bone 43: 119-125, 2008.

28. Giangregorio LM, Craven BC and Webber CE: Musculoskeletal changes in women with spinal cord injury: a twin study. J Clin Densitom 8: 347-351, 2005.

29. Schmid A, Huonker M, Stahl F, et al: Free plasma catecholamines in spinal cord injured persons with different injury levels at rest and during exercise. J Auton Nerv Syst 68: 96-100, 1998.

30. Vaziri ND, Pandian MR, Segal JL, Winer RL, Eltorai I and Brunnemann S: Vitamin D, parathormone and calcitonin profiles in persons with long-standing spinal cord injury. Arch Phys Med Rehabil 75: 766-769, 1994

31. Morse LR, Xu Y, Solomon B, et al: Severe spinal cord injury causes immediate multi-cellular dysfunction at the chondro-osseous junction. Transl Stroke Res 2: 643-650, 2011.

32. Pietschmann P, Pils P, Woloszczuk W, Maerk R, Lessan D and Stipicic J: Increased serum osteocalcin levels in patients with paraplegia. Paraplegia 30: 204-209, 1992. 
33. Morse L, Teng YD, Pham L, et al: Spinal cord injury causes rapid osteoclastic resorption and growth plate abnormalities in growing rats (SCI-induced bone loss in growing rats). Osteoporos Int 19: 645-652, 2008

34. Majumdar S, Kothari M, Augat P, et al: High-resolution magnetic resonance imaging: three-dimensional trabecular bone architecture and biomechanical properties. Bone 22: 445-454, 1998.

35. Jia Z, Zhu H, Li J, Wang X, Misra H and Li Y: Oxidative stress in spinal cord injury and antioxidant-based intervention. Spinal Cord 50: 264-274, 2012.

36. Sun Y, Shuang F, Chen DM and Zhou RB: Treatment of hydrogen molecule abates oxidative stress and alleviates bone loss induced by modeled microgravity in rats. Osteoporos Int 24: 969-978, 2013.

37. Fouad AA, Al-Sultan AI, Refaie SM and Yacoubi MT: Coenzyme Q10 treatment ameliorates acute cisplatin nephrotoxicity in mice. Toxicology 274: 49-56, 2010.

38. Demulder A, Guns M, Ismail A, Wilmet E, Fondu P and Bergmann P: Increased osteoclast-like cells formation in long-term bone marrow cultures from patients with a spinal cord injury. Calcif Tissue Int 63: 396-400, 1998.

39. Lee J, Hong YS, Jeong JH, et al: Coenzyme Q10 ameliorates pain and cartilage degradation in a rat model of osteoarthritis by regulating nitric oxide and inflammatory cytokines. PLoS One 8: e69362, 2013.

40. Jin HJ, Xue Y, Chen G and Wu ZY: Effect of coenzyme Q10 on the expression of tumor necrosis factor- $\alpha$ and interleukin-10 in gingival tissue of experimental periodontitis in rats. Zhonghua Kou Qiang Yi Xue Za Zhi 48: 660-663, 2013 (In Chinese).

41. Fouad AA and Jresat I: Hepatoprotective effect of coenzyme Q10 in rats with acetaminophen toxicity. Environ Toxicol Pharmacol 33: 158-167, 2012.

42. Lacey DL, Timms E, Tan HL, et al: Osteoprotegerin ligand is a cytokine that regulates osteoclast differentiation and activation Cell 93: 165-176, 1998.
43. Hsu H, Lacey DL, Dunstan CR, et al: Tumor necrosis factor receptor family member RANK mediates osteoclast differentiation and activation induced by osteoprotegerin ligand. Proc Natl Acad Sci USA 96: 3540-3545, 1999.

44. Simonet WS, Lacey DL, Dunstan CR, et al: Osteoprotegerin: a novel secreted protein involved in the regulation of bone density. Cell 89: 309-319, 1997.

45. Moon HJ, Ko WK, Jung MS, et al: Coenzyme q10 regulates osteoclast and osteoblast differentiation. J Food Sci 78: H785-H891, 2013.

46. Brömme D and Okamoto K: Human cathepsin $\mathrm{O}_{2}$, a novel cysteine protease highly expressed in osteoclastomas and ovary molecular cloning, sequencing and tissue distribution. Biol Chem Hoppe Seyler 376: 379-384, 1995.

47. Ho N, Punturieri A, Wilkin D, et al: Mutations of CTSK result in pycnodysostosis via a reduction in cathepsin $\mathrm{K}$ protein. J Bone Miner Res 14: 1649-1653, 1999.

48. Johnson MR, Polymeropoulos MH, Vos HL, Oetiz De Luna RI and Francomano CA: A nonsense mutation in the cathepsin K gene observed in a family with pycnodysostosis. Genome Res 6: 1050-1055, 1996.

49. Saftig P, Hunziker E, Wehmeyer O, et al: Impaired osteoclastic bone resorption leads to osteopetrosis in cathepsin-K-deficient mice. Proc Natl Acad Sci USA 95: 13453-13458, 1998.

50. Pennypacker BL, Oballa RM, Levesque S, Kimmel DB and Duong le T: Cathepsin K inhibitors increase distal femoral bone mineral density in rapidly growing rabbits. BMC Musculoskelet Disord 14: 344, 2013.

51. Xiao G, Jiang D, Ge C, et al: Cooperative interactions between activating transcription factor 4 and Runx2/Cbfa1 stimulate osteoblast-specific osteocalcin gene expression. J Biol Chem 280: 30689-30696, 2005.

52. Liu W, Toyosawa S, Furuichi T, et al: Overexpression of Cbfa1 in osteoblasts inhibits osteoblast maturation and causes osteopenia with multiple fractures. J Cell Biol 155: 157-166, 2001. 